\title{
Regional Multiproxy Climate Reconstruction for Southern South America: A new Research Initiative
}

\author{
Martin Grosjean ${ }^{1}$ and Ricardo Villalba ${ }^{2}$ \\ ${ }^{1}$ NCCR Climate, University of Bern, Switzerland; grosjean@giub.unibe.ch \\ ${ }^{2}$ Dept. of Dendrochronology \& Env. History, IANIGLA-CRICYT, Mendoza, Argentina; ricardo@lab.cricyt.edu.ar
}

Regional high-resolution multi-proxy climate reconstructions and associated uncertainties for the last ca. 1000 years is a priority area of future research within IGBP-PAGES (Wanner 2005). Considerable progress has been made in the reconstruction technique, in the handling of a wide range of high- and low-frequency proxy data, and in the quantity and quality of proxy data sets available at continental and northern hemispheric or global scale (e.g. Mann et al. 1998; Jones et al. 2001; Esper et al. 2002; Briffa and Osborn 2002; Luterbacher et al. 2004; Moberg et al. 2005). Regional reconstructions are particularly important since regional climate change and extremes exhibit much larger amplitudes than hemispherical and global reconstructions. The monthly to seasonal temperature multiproxy reconstruction for Europe since 1500 AD (Luterbacher et al. 2004; Xoplaki et al. 2005) and the drought reconstruction for the western US (Cook et al. 2004) have set new standards for regional scales. Similar studies are missing for other regions of the world.

Starting in October 2005 under the umbrella of PAGES, a collaborative longterm initiative will seek (i) to collate the large number of disperse already existing and new paleoclimate data sets (documentary data, early instrumental data, data from tree rings, glaciers and ice cores, high resolution marine and lake sediments, pollen data of peat cores etc.) for the last ca. 1000 years available for South America, and (ii) to use the Mann et al. (1998), Luterbacher et al. (2004) and Moberg et al. (2005) methodologies to work towards a regional reconstruction at different temporal and spatial resolution with associated uncertainties for southern South America.

This project is conceived as a collaborative initiative that will involve many research groups from different countries working within a

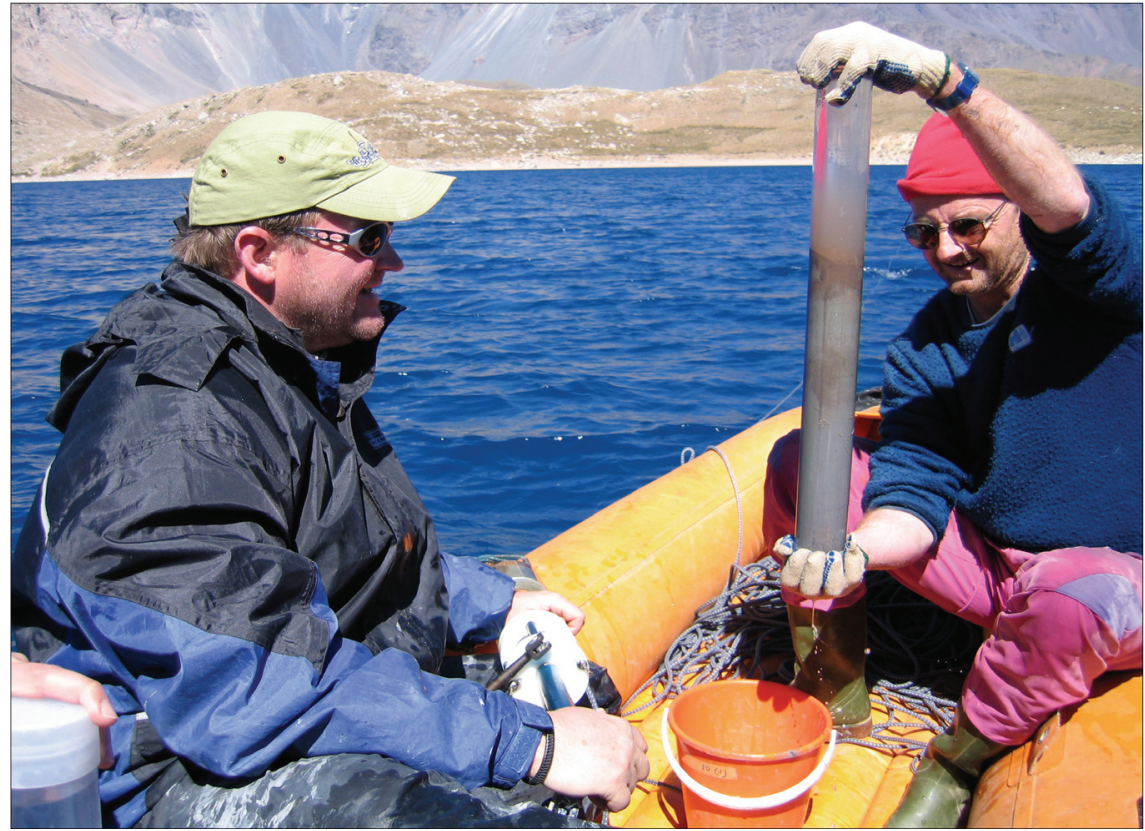

Fig. 1: Laguna Negra, high Andes of Central Chile. The potential contribution of sediments from small glacial lakes to high-resolution multiproxy climate reconstructions for the last milennium is currently explored in a joint Chilean -Swiss project (M. Grosjean U Bern, Micha Herzog UGZ Magdeburg).

common frame for a common goal. A first coordinative meeting will take place at Mendoza in October 2005 to set up the organizational frame and to discuss participation of groups in the project and contributions of data sets. A formal announcement and invitation for collaboration will follow thereafter. A first science meeting is planned for October 2006.

The initiative is coordinated by Ricardo Villalba (IANIGLA Mendoza, Argentina, PAGES SSC member) and Martin Grosjean (NCCR Climate, University of Bern, Switzerland).

If you wish to be on the mailing list, please contact Ricardo Villalba (ricardo@lab.cricyt.edu.ar) or Martin Grosjean (grosjean@giub.unibe. ch).

\section{REFERENCES}

Briffa, K.R. and Osborn T.J., 2002: Blowing Hot and Cold, Science, 295: 2227-2228

Cook, E.R., Woodhouse, C.A., Eakinn C.M., Meko, D.M. and Stahle, D.W., 2004: Long Term Aridity Changes in the Western United States, Science, 306: 1015-1018.

Esper, J., Cook, E.R. and Schweingruber F.H.

2002: Low-Frequency Signals in Long Tree-Ring
Chronologies for Reconstructing Past Temperature Variability, Science, 295: 2250-2253.

Jones, P.D., Osborn, T.J. and Briffa K.R., 2001: The Evolution of Climate Over the last Millenium, Sci-

Luterbacher J., Dietrich, D., Xoplaki, E., Grosjean, M. and Wanner H., 2004: European Seasonal and Annual Temperature Variability, Trends and Extremes Since 1500, Science, 303: 1499-1503.

Mann M.E., Bradley, R.S. and Hughes, M.K., 1998: Global-scale temperature patterns and climate forcing over the past six centuries, Nature, $\mathbf{3 9 2}$ : 779-787.

Moberg, A., Sonechkin, D. M., Holmgren, K., Datsenko, N. M. and Karlén, W., 2005: Highly variable Northern Hemisphere temperatures reconstructed from low- and high-resolution proxy data, Nature, 433: 613-617.

Wanner H., 2005: Call for a PAGES Initiative on Past Regional Variability, PAGES News, 13: 19-20.

\section{(2) Contribute:}

Is this your field of expertise? Scientists interested in getting further information on this effort should contact Ricardo Villalba (ricardo@lab.cricyt.edu.ar) or Martin Grosjean (grosjean@giub.unibe.ch). ence, 292: 662-667. 